\title{
Pollution, sources, and ecological-health risks of polycyclic aromatic hydrocarbons in coastal waters along coastline of China
}

Jian Lu, Cui Zhang, Jun Wu, Yichen Lin, Yuxuan Zhang, Xiaobin Yu \& Zhenhua Zhang

To cite this article: Jian Lu, Cui Zhang, Jun Wu, Yichen Lin, Yuxuan Zhang, Xiaobin Yu \& Zhenhua Zhang (2020) Pollution, sources, and ecological-health risks of polycyclic aromatic hydrocarbons in coastal waters along coastline of China, Human and Ecological Risk Assessment: An International Journal, 26:4, 968-985, DOI: 10.1080/10807039.2018.1548899

To link to this article: https://doi.org/10.1080/10807039.2018.1548899

\section{冓 Published online: 09 Jan 2019.}

Submit your article to this journal $\pi$

III Article views: 293

Q View related articles $\sqsubset$

View Crossmark data $[\pi$

Citing articles: 4 View citing articles $\sqsubset$ 


\title{
Pollution, sources, and ecological-health risks of polycyclic aromatic hydrocarbons in coastal waters along coastline of China
}

\author{
Jian Lu ${ }^{a, b, c}$, Cui Zhang ${ }^{a, b}$, Jun Wu ${ }^{b, d}$, Yichen Lin ${ }^{a, b}$, Yuxuan Zhang ${ }^{a, b}$, Xiaobin Yu ${ }^{a, b}$, \\ and Zhenhua Zhang ${ }^{\mathrm{e}}$
}

${ }^{a}$ Key Laboratory of Coastal Environmental Processes and Ecological Remediation, Yantai Institute of Coastal Zone Research, Chinese Academy of Sciences, Yantai, Shandong, China; ${ }^{b}$ University of Chinese Academy of Sciences, Beijing, China; 'Center for Ocean Mega-Science, Chinese Academy of Sciences, Qingdao, Shandong, China; ${ }^{d}$ Qinghai Institute of Salt Lakes, Chinese Academy of Sciences, Xining,

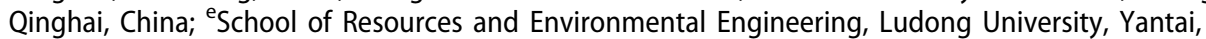
Shandong, China

\begin{abstract}
This study investigated the distribution, sources, and potential risks of polycyclic aromatic hydrocarbons (PAHs) in coastal waters along over $18,000 \mathrm{~km}$ of coastline in China. Concentrations of PAHs in coastal waters ranged from 141.99 to $717.72 \mathrm{ng} / \mathrm{L}$. Approximately $84.38 \%$ of sampling sites were determined at moderate PAH pollution level. PAHs in coastal waters at most of sampling sites mainly originated from combustion based on characteristic ratios of PAHs. Ecological risks posed by PAHs in coastal waters were evaluated as high level at $59.38 \%$ of sampling sites and moderate level at $40.63 \%$ of sampling sites although toxic equivalent quotients of PAHs only ranged from 2.86 to $126.52 \mathrm{ng} / \mathrm{L}$ benzo[a]pyrene that was not detected at all sampling sites. Maximal cancer risk/hazard quotient of total PAHs in coastal waters for adults and children reached $6.34 \times 10^{-4} / 5.85 \times 10^{-2}$ and $2.25 \times 10^{-3} / 7.72 \times 10^{-2}$, respectively. PAHs exerted high cancer risks for children at $31.25 \%$ of sampling sites. Health risks posed by PAHs in coastal waters of this study were higher than those of Japan, Belgium, Greece, Italy, Spain, USA, and Australia, but much lower than those of Singapore, Iran, Brazil, and Egypt. These findings indicate that PAH pollution has become a crucial stress affecting the sustainable development of coastal regions.
\end{abstract}

\section{ARTICLE HISTORY}

Received 6 September 2018 Revised manuscript accepted 13 November 2018

\section{KEYWORDS}

polycyclic aromatic hydrocarbons; coastal waters; ecological risks; health risk assessment; source apportionment

\section{Introduction}

Polycyclic aromatic hydrocarbons (PAHs), ubiquitous in the environment, are a group of over 100 individual persistent organic compounds possessing two or more fused aromatic rings (Barro et al. 2009). PAHs have exhibited potential/proven carcinogenicity and genotoxicity (Capone and Bauer 1992; Purcaro et al. 2013), long-distance transportation features (Pandey et al. 2011), high persistence (Akhbarizadeh et al. 2016; Marini and Frapiccini 2013), poor biodegradation (Akhbarizadeh et al. 2016), high toxicity (McGrath and Di

CONTACT Jian Lu $\otimes$ jlu@yic.ac.cn $=$ Key Laboratory of Coastal Environmental Processes and Ecological Remediation, Yantai Institute of Coastal Zone Research, Chinese Academy of Sciences, Yantai, Shandong 40032, China Color versions of one or more of the figures in the article can be found online at www.tandfonline.com/bher.

(4) Supplemental data for this article can be accessed here. 
Toro 2009; Qin et al. 2013), and significant bioaccumulation (Li et al. 2016) to attract increasing attention. Moreover, 16 PAHs have been selected as priority pollutants by the United States Environmental Protection Agency (USEPA) owing to their carcinogenicity, toxicity, and mutagenicity (Zheng et al. 2016; USEPA 2014). Furthermore, health issues including health risks of PAHs have also become scientific and public-concerning hotspot in recent years (Akhbarizadeh et al. 2016; Qamar et al. 2017; Rajasekhar et al. 2018; SarriaVilla et al. 2016). Therefore, it is critical to explore the potential ecological and health risks posed by PAHs when paying attention to those pollutants in aquatic systems.

It is generally acceptable that PAHs originate from pyrogenic, petrogenic, and diagenetic sources (Li et al. 2015; Mostafa et al. 2009). Thereafter, PAHs are also categorized into pyrogenic group that mainly originates from incomplete combustion of fuels including coal, petroleum, wood, and grass (Birks et al. 2017; Mostafa et al. 2009), petrogenic group that is mainly from petroleum sources such as fuels, crude oil, and lubricants (Birks et al. 2017; Mostafa et al. 2009), and diagenetic group that is derived from biogenic precursors (Mostafa et al. 2009). Different sources address different distribution of PAHs in the environment (Birks et al. 2017) to exert various impacts to the ecosystem and human beings. Therefore, it is of important concern to determine the sources of PAHs in the environment, especially the aquatic systems.

Coastal regions with intensive land-ocean interactions are not only the critical ecologically fragile regions but also the most important regions for human health and social sustainability because over $45 \%$ of people around the world live within approximately $100 \mathrm{~km}$ of global coastlines (Zhu et al. 2017). Coastal regions cover $13 \%$ of the total landmass and contain $40 \%$ of population in China (Meng et al. 2017). They are also the areas with the fastest developing pace and the extensive anthropogenic activities in China. Coastal regions are currently facing two critical issues including rapidly increasing human populations and continually compressed ecosystem services in these ecologically fragile areas (Dennison 2008). Environmental pollution has become a crucial stress affecting the critical ecologically fragile regions such as the coastal zone and the Qinghai-Tibet Plateau due to the rapid economic development and extensive anthropogenic activities (Wang et al. 2018; Wen et al. 2018; Wu et al. 2016; Wu et al. 2018; Zhu et al. 2017). PAHs in the waters of some local bays, gulfs, and lakes have exerted considerable ecological risks to the aquatic ecosystems (Agah et al. 2017; Li et al. 2015; Qin et al. 2013; Ranjbar Jafarabadi et al. 2017). Therefore, information on the pollution and ecological-health risks of PAHs in the coastal waters of the coastal zone at a national or continental scale is critical for regional sustainability. The objectives of this study are to investigate the distribution characteristics, analyze the possible sources, and discuss the potential risks of PAHs in the coastal waters along the over $18,000 \mathrm{~km}$ of coastline in China. The final aim is to provide comprehensive insight for the environment pollution and sustainable development in the coastal regions.

\section{Methods and materials}

\section{Chemicals and reagents}

The 16 priority PAH congeners including naphthalene (Naph), acenaphthylene (Acy), acenaphthene (Ace), fluorene (Flu), phenanthrene (Phe), anthracene (Anth), pyrene 
(Pyr), fluoranthene (Flt), benzo[a]anthracene (BaA), chrysene (Chry), benzo[b]fluoranthene $(\mathrm{BbF})$, benzo[k]fluoranthene $(\mathrm{BkF})$, benzo[a]pyrene $(\mathrm{BaP})$, indeno [1,2,3-cd]pyrene $(\mathrm{InP})$, dibenzo[a,h]anthracene (DbA), and benzo[g,h,i]perylene (BghiP) were analyzed. Standard mixture stock solution of $16 \mathrm{PAH}$ congeners with concentration of $1000 \mu \mathrm{g} / \mathrm{L}$ and mixture stock solution of deuterated internal standards including phenanthrene- $\mathrm{d}_{10}$, chrysene- $\mathrm{d}_{12}$, naphthalene- $d_{8}$, perylene- $d_{12}$, and acenaphthene- $d_{10}$ with concentration of $2000 \mathrm{mg} / \mathrm{L}$ were purchased from o2si smart solutions, LLC (Charleston, SC, USA). Dichloromethane, n-hexane, and methanol used for sample preparation and analysis were HPLC grade and obtained from MREDA (Mreda Technology Inc., USA). Anhydrous sodium sulfate was baked at $450{ }^{\circ} \mathrm{C}$ for $8 \mathrm{~h}$ and stored in sealed containers.

\section{Study area and sample strategy}

Sampling was performed in November of 2017. Mixed-surface coastal water sample with volume of $30 \mathrm{~L}$ was composed of six subsamples with volume of $5 \mathrm{~L}$ collected along the coastline of each sampling site at the distance interval of $5 \mathrm{~m}$ by using pre-cleaned amber glass sample bottles and then being quickly transported back to the laboratory for further analysis. Coastal water samples were collected from 32 sampling sites along Chinese coastline covering all the four coastal regions in China including Bohai Area (B1-B8), Yellow Sea Area (Y1-Y11), East China Sea Area (E1-E6), and South China Sea Area (S1-S7) (Figure S1 in the online supplementary information (SI)). Over $45 \%$ of global people live in the coastal regions, suggesting that some functional zones such as estuaries, gulfs, bays, zones, bathing beaches, and ports are critical to human health and ecosystems. Moreover, mariculture has become one of the most important aquacultures in the coastal regions (Gao et al. 2012), illustrating that mariculture also has important impacts on human health and sustainable ecosystems. Therefore, sampling locations involved the main estuaries, gulfs, bays, maricultural zones, bathing beaches, and ports along the coastline in China to represent the important functional zones of the coastal regions affecting the ecosystem and human health.

\section{Sample preparation and analysis}

The water samples with volume of $1 \mathrm{~L}$ were firstly filtered using $0.45-\mu \mathrm{m}$ membrane filters (Pall Life Sciences, Ann Arbor, MI, USA). Subsequently, the filtrated samples were spiked with a $5 \mu \mathrm{L}$ of deuterated internal standard mixture solution $(100 \mathrm{mg} / \mathrm{L})$ before solid phase extraction (SPE) to compensate the loss of target analytes during the extraction process as well as analysis procedure. The water samples were percolated under very low vacuum through the Oasis HLB 6cc/200 mg cartridges (Waters Corp., Mill-ford, MA) that were conditioned with $10 \mathrm{~mL}$ of dichloromethane, $10 \mathrm{~mL}$ of methanol, and $10 \mathrm{~mL}$ of ultrapurewater. After extraction, $10 \mathrm{~mL}$ of dichloromethane was passed through the cartridges to elute and yield a fraction containing PAHs. The eluent was concentrated to nearly dry under a gentle nitrogen stream after passing through anhydrous sodium sulfate and re-dissolved in $1 \mathrm{~mL}$ of $\mathrm{n}$-hexane for Gas Chromatography-Mass Spectrometer (GC-MS) analysis.

Samples were analyzed by Agilent 7820A GC system (Agilent technologies Inc., Palo Alto, CA, USA) with a M7 single quadrupole MS system from Persee (Beijing, China). 
A $30 \mathrm{~m} \times 0.25 \mathrm{~mm}$ I.D. DB-5MS column (Agilent J\&W Scientific, Folsom, CA, USA) coated with $5 \%$ diphenylpoly dimethyl siloxane (film thickness $0.25 \mu \mathrm{m}$ ) was employed for separation of target compounds during analysis. The injector was operating at $280{ }^{\circ} \mathrm{C}$ in splitless mode. Helium ( $>99.999 \%$ pure) was used as carrier gas at $1.0 \mathrm{~mL} /$ min during the whole run. The temperatures of the transfer line and ion source were held at 280 and $230^{\circ} \mathrm{C}$, respectively. The column oven temperature program started at $40^{\circ} \mathrm{C}$ for $3 \mathrm{~min}$, then programed to $200^{\circ} \mathrm{C}$ at $25^{\circ} \mathrm{C} / \mathrm{min}$, and held for $5 \mathrm{~min}$, finally to $290^{\circ} \mathrm{C}$ at $8^{\circ} \mathrm{C} / \mathrm{min}$ rate, and held for $10 \mathrm{~min}$ to comprise a total runtime of $35.65 \mathrm{~min}$, including a 7 -min solvent cut for all analyses.

All target compounds were identified by full scan mode (m/z 50-400) based on their mass spectra and GC retention times. Subsequent acquisition and quantification were performed by a time scheduled selective ion monitoring (SIM) program. The quantitative and qualitative ions for 16 PAHs were presented in Table S1.

\section{Quality control and quality assurance}

Quality control procedures in the laboratory included the analyses of method blanks (solvent), spiked blanks (solvent spiked by PAH standard mixture solution), and sample in duplicate. The recovery was checked by analyzing water samples spiked with known amount of $\mathrm{PAH}$ standard. Recoveries of 16 PAHs were in the range of 79.68\%-116.84\%. Concentrations of PAHs were all corrected according to the recoveries of internal standards. The limit of detection (LOD) for PAHs ranged from 0.34 to $3.81 \mathrm{ng} / \mathrm{L}$. The information on retention time, mean recovery, relative standard deviation (RSD), and LOD was shown in Table S1.

\section{Source apportionment}

Several molecular ratios can serve as indictors to determine the potential sources of PAHs in water (Agah et al. 2017; Akhbarizadeh et al. 2016; Birks et al. 2017; Budzinski et al. 1997; Li et al. 2015; Li et al. 2017; Liu et al. 2016; Ranjbar Jafarabadi et al. 2017; Yuan et al. 2017; Yunker et al. 2002; Zhang et al. 2016; Zheng et al. 2016). This study selected molecular ratios of Flt/(Flt + Pyr), BaA/(BaA + Chry), Anth/ (Anth + Phe), InP/(InP + BghiP), Flt/Pyr, Phe/Anth, and LMW (low-molecular-weight PAHs, 2-3 rings)/HMW (high-molecular-weight PAHs, 4-6 rings) to evaluate the origin of PAHs in coastal waters. The diagenetic source of PAHs was not discussed in this study because this source is scarce in the environment (Mostafa et al. 2009) and typical indicator (perylene) that is not listed in the priority pollutants was not monitored. Detailed characteristic values of selected ratios for source apportionment were referred to Table S2.

\section{Ecological risk assessment}

Potential ecological risks of PAHs in coastal waters were evaluated using risk quotients (RQs). RQs of PAHs were calculated according to the following equations (Cao et al. 2010; Li et al. 2015; Ranjbar Jafarabadi et al. 2017; Sun et al. 2009): 


$$
\begin{gathered}
R Q_{i(N C s)}=\frac{C_{i}}{C_{i Q V(N C s)}} \\
R Q_{i(M P C s)}=\frac{C_{i}}{C_{i Q V(M P C s)}} \\
R Q_{t(N C s)}=\sum_{i=1}^{n} R Q_{i(N C s)}\left(R Q_{i(N C s)} \geq 1\right) \\
R Q_{t(M P C s)}=\sum_{i=1}^{n} R Q_{i(M P C s)}\left(R Q_{i(M P N C s)} \geq 1\right)
\end{gathered}
$$

where $R Q_{i(N C s)}$ and $R Q_{i(M P C s)}$ refer to risk quotients based on the negligible concentrations (NCs) and the maximum permissible concentrations (MPCs) of individual PAHs in water, respectively; $C_{i}$ refers to the concentration of individual PAHs in water; $C_{i Q V(N C s)}$ and $C_{i Q V(M P C s)}$ are the quality values of NCs and MPCs of PAHs in water, respectively; $n$ is the number of PAH congeners; $R Q_{t(N C s)}$ and $R Q_{t(M P C s)}$ refer to sum of individual risk quotient that is equal or greater than 1 based on NCs and MPCs of individual PAHs in water, respectively. The equivalent values of NCs and MPCs of individual PAHs in water and risk classification thresholds are referred to Tables S3 and S4. Pollution of PAHs in water can be classified into four levels according to criterion listed in Table S4 (Li et al. 2015). Therefore, this study also evaluated pollution levels of PAHs in coastal waters.

\section{Toxic evaluation}

The toxicity of each PAH congener was calculated based on toxic equivalent factor (TEF) method and the total toxicity of PAHs was the sum of individual PAH congener toxicity as the following equation (Cao et al. 2010; Li et al. 2015; Qamar et al. 2017; Zheng et al. 2014):

$$
T E Q=\sum_{i=1}^{n} C_{i} \times T E F_{i}
$$

where $T E Q$ is toxic equivalent quotient; $T E F_{i}$ is the toxic equivalent factor of each $\mathrm{PAH}$ congener relative to $\mathrm{BaP}$. The TEF values were listed in Table S4 and the maximum values were taken if $T E F$ values of the same congener appeared variously in different references.

\section{Health risk assessment}

Dermal contact such as swimming, surfing, diving, and working in surface seawater is the main health exposure path of PAHs in coastal waters because coastal waters are not suitable to drink. Therefore, this study adopted cancer and non-cancer risks through dermal contact to evaluate the potential health risks of PAHs. The detailed information on cancer risk (CR) and hazard quotient (HQ) of individual pollutant is shown by the following equations (Akhbarizadeh et al. 2016; Rajasekhar et al. 2018; Sarria-Villa et al. 
2016; USEPA 2004):

$$
\begin{aligned}
C R(\text { individual })= & D A D \times \frac{S F_{O}}{G I A B S}=D A_{\text {event }} \times \frac{E V \times E D \times E F \times S A}{B W \times A T} \times \frac{S F_{O}}{G I A B S} \\
= & 2 \times F A \times K_{P} \times C_{W} \times \sqrt{\frac{6 \times \tau_{\text {event }} \times t_{\text {event }}}{\pi}} \\
& \times \frac{E V \times E D \times E F \times S A}{B W \times A T} \times \frac{S F_{O}}{G I A B S}
\end{aligned}
$$

$$
\begin{aligned}
H Q(\text { individual })= & D A D \times \frac{1}{R f D_{O} \times G I A B S}=D A_{\text {event }} \times \frac{E V \times E D \times E F \times S A}{B W \times A T} \times \frac{1}{R f D_{O} \times G I A B S} \\
= & 2 \times F A \times K_{P} \times C_{W} \times \sqrt{\frac{6 \times \tau_{\text {event }} \times t_{\text {event }}}{\pi} \times \frac{E V \times E D \times E F \times S A}{B W \times A T}} \\
& \times \frac{1}{R f D_{O} \times G I A B S}
\end{aligned}
$$

$$
\begin{aligned}
C R & =\sum C R(\text { individual }) \\
H Q & =\sum H Q(\text { individual })
\end{aligned}
$$

where $D A D$ and $D A_{\text {event }}$ refer to dermal absorbed dose and absorbed dose per event, respectively; $E V, E D$, and $E F$ refer to the event frequency, exposure duration, and exposure frequency, respectively; $S A$ represents skin surface area; $B W$ is body weight; $A T$ represents average lifespan; $S F_{O}$ is oral slope factor; GIABS refers to the fraction of pollutant absorbed in gastrointestinal tract; $R f D_{O}$ is oral reference dose; $F A$ refers to the fraction of absorbed water; $K_{P}$ stands for dermal permeability coefficient of pollutant; $C_{W}$ refers to concentration of PAHs in coastal water; $\tau_{\text {event }}$ is lag time per event; $t_{\text {event }}$ refers to event duration. The values of parameters were obtained from the references (Akhbarizadeh et al. 2016; Man et al. 2013; Rajasekhar et al. 2018; Sarria-Villa et al. 2016; USEPA 2004; USEPA 2016) and listed in Table S5.

To evaluate the level of the health risks posed by PAHs at a global scale, data on the highest concentrations of PAHs in coastal waters of other countries were cited from literatures (Ahmed et al. 2017; Akhbarizadeh et al. 2016; Cocci et al. 2017; Monteyne et al. 2013; Obbard et al. 2007; Sánchez-Avila et al. 2010; Sankoda et al. 2017; Shaw et al. 2004; Silva et al. 2007; Valavanidis et al. 2008; Williams et al. 2017) to assess health risks of PAHs for adults and children living in corresponding countries. The highest concentration of PAHs in this study was adopted to evaluate health risks for comparison. 


\section{Results and discussion}

\section{Distribution features of PAHs in coastal waters along Chinese coastline}

The total concentrations of PAHs in coastal waters ranged from 141.99 to $717.72 \mathrm{ng} / \mathrm{L}$ with the average value of $390.06 \mathrm{ng} / \mathrm{L}$ (Figure 1a). The concentration ranges of 2-ring, 3-ring, 4-ring, 5-ring, and 6-ring PAHs were 1.52-269.52, 23.55-475.28, 17.02-197.12, $\mathrm{ND}$ (not detected)-292.45, and $7.63-165.19 \mathrm{ng} / \mathrm{L}$ with the average concentrations of 69.32, 129.83, 75.33, 75.06, and $40.53 \mathrm{ng} / \mathrm{L}$, respectively (Figure 1a). Composition proportions of 2-ring, 3-ring, 4-ring, 5-ring, and 6-ring PAHs were in the ranges of $0.47 \%-43.07 \%, 13.68 \%-70.21 \%, 7.58 \%-41.52 \%, 0.00 \%-44.84 \%$, and $2.17 \%-39.42 \%$ with average values of $16.10 \%, 34.30 \%, 20.66 \%, 19.03 \%$, and $9.91 \%$, respectively. Concentrations of LMW PAHs ranged from 44.95 to $516.43 \mathrm{ng} / \mathrm{L}$ with the average value of $199.15 \mathrm{ng} / \mathrm{L}$, while those of HMW PAHs were in the range of $69.12-470.27 \mathrm{ng} / \mathrm{L}$ with a mean value of $190.92 \mathrm{ng} / \mathrm{L}$. The maximal proportion of LMW and HMW PAHs reached $77.05 \%$ and $70.37 \%$ with average proportions of $50.40 \%$ and $49.60 \%$, respectively. Interestingly, PAHs in coastal waters near many beaches such as Y5-Y7 and S3-S5 were mainly composed by LMW PAHs which were easy to diffuse in coastal waters from the adjacent area and might be also introduced by pleasure-boats and/or
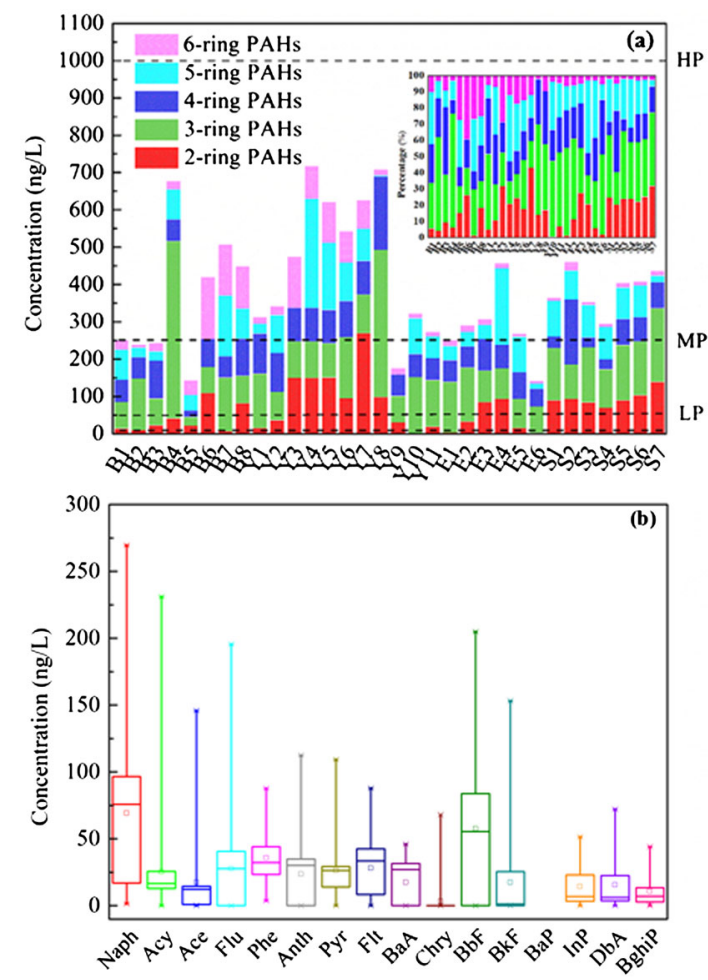

Figure 1. Concentrations (a) and composition box plot of PAHs (b) in coastal waters of the study area. LP, MP, and HP refer to light pollution, moderate pollution, and heavy pollution, respectively. In each box, the bottom and top of the box illustrate the 25th and 75th percentiles; the mid-line of box means the median value; the small square represents the average value of the target compound; the bottom and top of the whiskers refers to the minimal and maximal concentrations. 
aquaculture vessels. Distribution and composition of PAHs in coastal waters along Chinese coastline exhibited significant site-specific feature (Figure 1). PAHs in most of coastal water samples collected from Haihe Estuary (B4) and Shandong Peninsula (B6, B7, B8, Y3, Y4, Y5, Y6, Y7, and Y8) showed high concentrations.

Concentrations of individual LMW PAH congeners ranged from below detection limit (Acy, Ace, Flu, and Anth at multiple sites) to 269.52 (Naph at Y5) ng/L while those of individual HMW PAH congeners ranged from below detection limit (Pyr, Flt, BaA, Chry, $\mathrm{BbF}, \mathrm{BkF}, \mathrm{BaP}, \mathrm{InP}$, and $\mathrm{DbA}$ at multiple sites) to 204.90 (BbF at E4) ng/L (Figures $1 \mathrm{~b}$ and S2). BaP was not detected at all sampling sites, while Naph, Phe, BghiP, InP, and $\mathrm{DbA}$ were the most frequently detected with detection percents of $100 \%, 100 \%, 100 \%$, 93.75\%, and 93.75\%, respectively. Generally, 3-ring PAHs served as the dominant congeners of LMW PAHs, contributing to 50.23\%-99.00\% of LMW PAHs for $75.00 \%$ of sampling sites, whereas 4-ring and 5-ring PAHs were the dominant groups for HMW PAHs, contributing to $59.76 \%-95.09 \%$ of HMW PAHs for $93.75 \%$ of sampling sites.

Based on pollution evaluation criterion ( $\mathrm{Li}$ et al. 2015), $84.38 \%$ of sampling sites were determined at moderate $\mathrm{PAH}$ pollution, while the rest were at light pollution level (Figure 1a). Considering coastal water samples were all collected from the sites with extensive anthropogenic activities, the pollution status deserved more attention.

\section{Source apportionment of PAHs in coastal waters along Chinese coastline}

Seven characteristic ratios were adopted for source apportionment of PAHs in coastal waters (Figure 2) to avoid the possible false-positive and false-negative phenomena caused by single index. For ratios with value of 0 or error (divided by 0 ) due to nondetected congeners, source of PAHs was determined according to the remaining ratios. PAHs of some sampling sites such as B1-B8, Y1-Y2, E4-E6, and S1-S7 mainly originated from coal and biomass combustion based on identical evaluation results of Flt/ (Flt + Pry) and InP/(InP + BghiP). PAHs of some sampling sites such as Y4-Y6, Y10Y11, and E1-E3 possibly originated from combustion of petroleum, coal, and biomass due to inconsistent evaluation results of Flt/(Flt + Pry $)$ and InP/(InP + BghiP). PAHs of Y9 might originate petroleum combustion based on results of $\mathrm{InP} /(\mathrm{InP}+\mathrm{BghiP})$. The combustion was the main source of PAHs for most of sampling sites along the coastline, indicating the great influence of anthropogenic activities on the pollution of coastal waters. The evaluation results were reasonable because sampling occurred in late autumn and early winter during which combustion frequently occurred for heating. According to previous investigation, combustion had been identified as the main source of PAHs in the South China Sea (Cai et al. 2017).

\section{Potential ecological risks of PAHs in coastal waters along Chinese coastline}

Potential ecological risks of individual PAH congeners and total PAHs in coastal waters of the study area were calculated and expressed as risk quotients including $R Q_{(N C s)}$ and $R Q_{(M P C s)}$ (Table 1 and Figure $\mathrm{S} 3$ ). Except $\mathrm{BaP}$ that was not detected in this study, $R Q_{(N C s)}$ of individual PAHs ranged from $\mathrm{ND}$ to 2049.03 (BbF at $\mathrm{E} 4$ ) with the average values from 1.02 (Chry) to $574.86(\mathrm{BbF})$, while $R Q_{(M P C s)}$ of individual PAHs ranged 

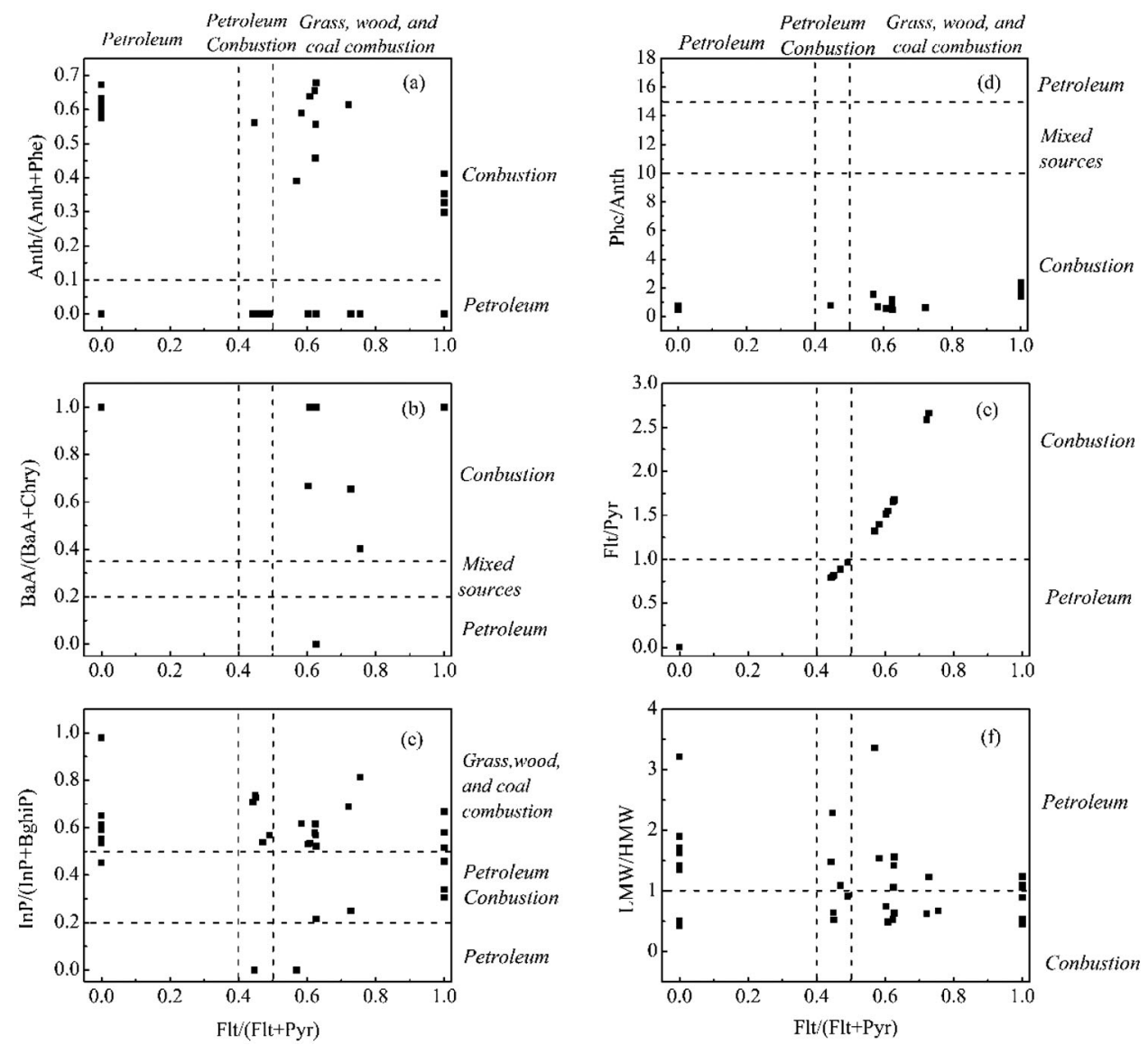

Figure 2. Cross plots of PAHs for the ratios of (a) Anth/(Anth + Phe) vs. Flt/(Flt $+\mathrm{Pyr})$, (b) $\mathrm{BaA} /$ (BaA + Chry) vs. Flt/(Flt + Pyr), (c) $\operatorname{lnP} /(\operatorname{lnP}+$ BghiP) vs. Flt/(Flt $+\mathrm{Pyr}),(\mathrm{d}) \mathrm{Phe} /$ Anth vs. Flt/(Flt $+\mathrm{Pyr})$, (e) Flt/Pyr vs. Flt/(Flt + Pyr), and (f) LMW/HMW vs. Flt/(Flt + Pyr).

Table 1. Statistical summary of ecological risk assessment on PAHs in coastal waters.

\begin{tabular}{|c|c|c|c|c|c|c|c|c|c|c|c|}
\hline \multirow[b]{2}{*}{ Chemical } & \multicolumn{4}{|c|}{$R Q_{i(N C s)}$ or $R Q_{t(N C s)}$} & \multicolumn{4}{|c|}{$R Q_{i(M P C S)}$ or $R Q_{t(M P C S)}$} & \multicolumn{3}{|c|}{ Risk level percent (\%) } \\
\hline & Mean & Min & Med & Max & Mean & Min & Med & Max & Low & Moderate & High \\
\hline Naphthalene (Naph) & 5.78 & 0.13 & 6.31 & 22.46 & 0.06 & 0.001 & 0.06 & 0.22 & 15.63 & 84.38 & 0.00 \\
\hline Acenaphthylene (Acy) & 36.12 & 0.00 & 23.79 & 330.16 & 0.36 & 0.00 & 0.24 & 3.30 & 18.75 & 75.00 & 6.25 \\
\hline Acenaphthene (Ace) & 24.89 & 0.00 & 17.50 & 208.28 & 0.25 & 0.00 & 0.17 & 2.08 & 25.00 & 68.75 & 6.25 \\
\hline Fluorene (Flu) & 39.66 & 0.00 & 39.77 & 279.20 & 0.40 & 0.00 & 0.40 & 2.79 & 34.38 & 62.50 & 3.13 \\
\hline Phenanthrene (Phe) & 11.91 & 1.23 & 10.75 & 29.25 & 0.12 & 0.012 & 0.11 & 0.29 & 0.00 & 100.00 & 0.00 \\
\hline Anthracene (Anth) & 33.76 & 0.00 & 43.20 & 160.50 & 0.34 & 0.00 & 0.43 & 1.61 & 37.50 & 59.38 & 3.13 \\
\hline Pyrene (Pyr) & 37.35 & 0.00 & 37.62 & 156.07 & 0.37 & 0.00 & 0.38 & 1.56 & 18.75 & 78.13 & 3.13 \\
\hline Fluoranthene (Flt) & 9.40 & 0.00 & 11.18 & 29.29 & 0.09 & 0.00 & 0.11 & 0.29 & 25.00 & 75.00 & 0.00 \\
\hline Benz[a]anthracene $(\mathrm{BaA})$ & 175.18 & 0.00 & 271.21 & 460.70 & 1.75 & 0.00 & 2.71 & 4.61 & 46.88 & 0.00 & 53.13 \\
\hline Chrysene (Chry) & 1.02 & 0.00 & 0.00 & 20.02 & 0.01 & 0.00 & 0.00 & 0.20 & 87.50 & 12.50 & 0.00 \\
\hline Benzo[b]fluoranthene (BbF) & 574.86 & 0.00 & 555.30 & 2049.03 & 5.75 & 0.00 & 5.55 & 20.49 & 28.13 & 0.00 & 71.88 \\
\hline Benzo[k]fluoranthene (BkF) & 43.93 & 0.00 & 3.32 & 383.15 & 0.44 & 0.00 & 0.03 & 3.83 & 40.63 & 53.13 & 6.25 \\
\hline Benzo[a]pyrene (BaP) & 0.00 & 0.00 & 0.00 & 0.00 & 0.00 & 0.00 & 0.00 & 0.00 & 100.00 & 0.00 & 0.00 \\
\hline Indeno[1,2,3-cd]pyrene (InP) & 35.84 & 0.00 & 17.19 & 128.46 & 0.36 & 0.00 & 0.17 & 1.28 & 6.25 & 81.25 & 12.50 \\
\hline Dibenz[a,h]anthracene (DbA) & 31.07 & 0.00 & 12.22 & 144.47 & 0.31 & 0.00 & 0.12 & 1.44 & 6.25 & 84.38 & 9.38 \\
\hline Benzo[ghi]perylene (BghiP) & 35.51 & 0.54 & 23.56 & 147.05 & 0.36 & 0.005 & 0.24 & 1.47 & 0.00 & 90.63 & 9.38 \\
\hline$\Sigma$ PAHs & 1096.22 & 470.16 & 1102.73 & 2491.94 & 8.49 & 1.753 & 8.47 & 22.74 & 0.00 & 40.63 & 59.38 \\
\hline
\end{tabular}

Note: Min, Med, and Max mean minimal value, median value, and maximal value, respectively. 

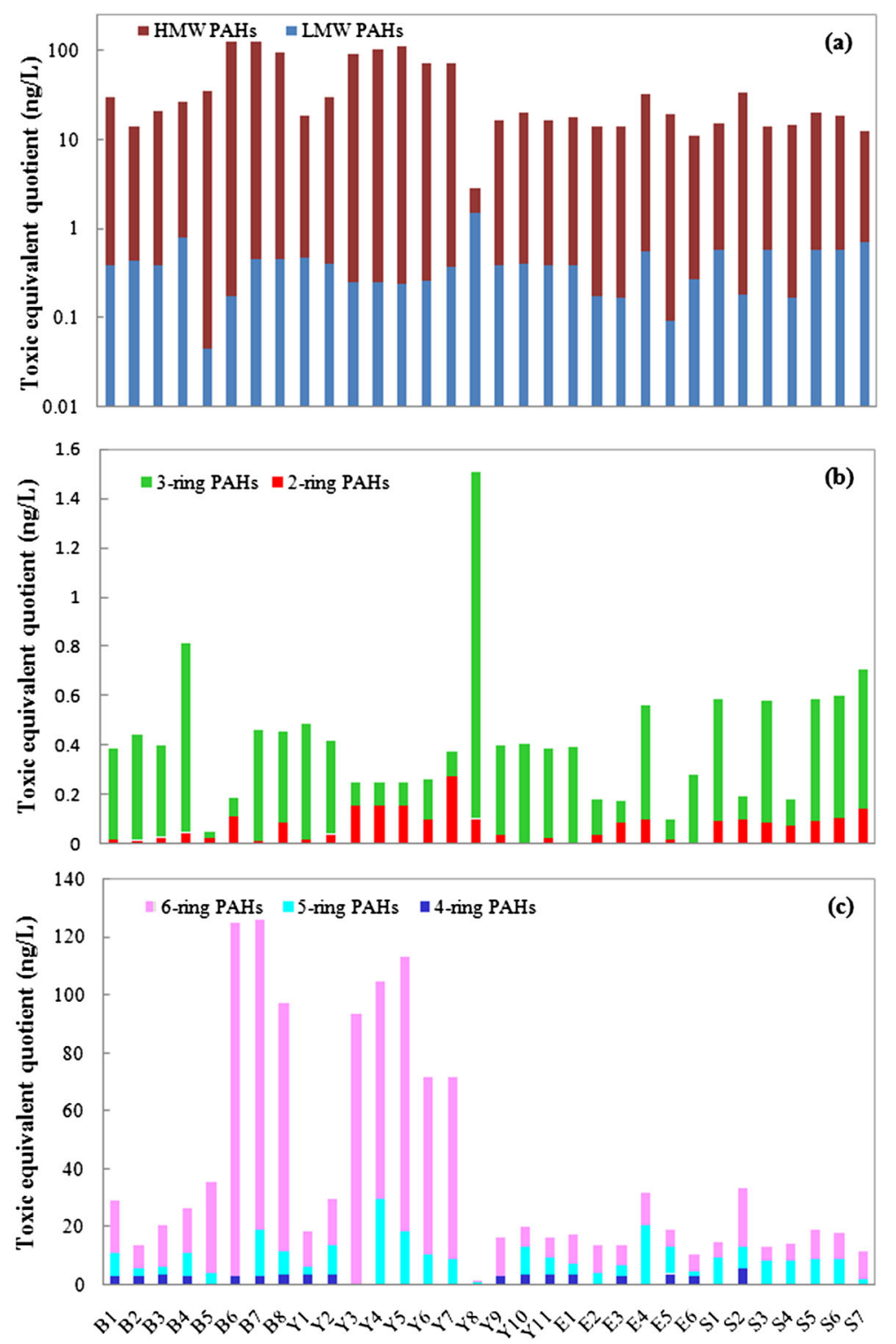

Figure 3. Toxic equivalent quotients and corresponding compositions for (a) total PAHs, (b) lowmolecular-weight (LMW) PAHs, and (c) high-molecular-weight (HMW) PAHs in coastal waters.

from ND to 20.49 (BbF at E4) with the average values from 0.01 (Chry) to 5.75 (BbF). According to evaluation criterion (Cao et al. 2010), BaP showed the lowest ecological risks since it was not detected. HMW PAHs including BbF, BaA, InP, DbA, and BghiP were the individual $\mathrm{PAH}$ congeners that exhibited high ecological risks to the ecosystems. $\mathrm{BbF}$ and $\mathrm{BaA}$ exerted high risks to $71.88 \%$ and $53.13 \%$ of sampling sites when comprehensively considering $R Q_{(N C s)}$ and $R Q_{(M P C s)}$, respectively. InP, DbA, and BghiP exerted high risks to $12.50 \%, 9.38 \%$, and $9.38 \%$ of sampling sites and moderate risks to $81.25 \%, 84.38 \%$, and $90.63 \%$ of sampling sites, respectively. LMW PAH congeners mainly exhibited moderate ecological risks to the ecosystems. 
Maximal $R Q_{(N C s)}$ and $R Q_{(M P C s)}$ of total PAHs reached 2491.94 and 22.74 with the average values of 1096.22 and 8.49, respectively. HMW PAHs mainly including BbF and BaA contributed significant proportion to $R Q_{(M P C s)}$ of total PAHs. All individual PAH congeners with concentrations exceeding their corresponding NCs contributed $R Q_{(N C s)}$ of total PAHs. Total PAHs exerted high risks to $59.38 \%$ of sampling sites and moderate risks to $40.63 \%$ of sampling sites based on $R Q_{(N C s)}$ and $R Q_{(M P C s)}$, more serious than individual congeners. Complex relationship might exist among the individual PAHs when they cooccurred in the environment and exerted potential risks to the ecosystems. Therefore, it is more reasonable to use $R Q_{(N C s)}$ and $R Q_{(M P C s)}$ of total PAHs to explore their potential ecological risks.

\section{Toxicity of PAHs in coastal waters along Chinese coastline}

Toxicity of PAHs in coastal waters was expressed as TEQs relative to the reference congener $\mathrm{BaP}$ that is a carcinogenic compound (Figure 3). The TEQs of total PAHs ranged from 2.86 to $126.52 \mathrm{ng} / \mathrm{L} \mathrm{BaP}$ with the average value of $39.99 \mathrm{ng} / \mathrm{L} \mathrm{BaP}$. HMW PAHs were the dominant toxicity contributor of PAHs, accounting for $94.41 \%-99.87 \%$ of total TEQs for sampling sites except Y8 where DbA and InP were not detected (Figure 3a). Except six sampling sites (B6, Y3, Y4, Y5, Y7, and S2), 3-ring PAHs served as dominant contributor for toxicity of LMW PAHs in the remaining sampling sites (Figure $3 \mathrm{~b}$ ). These six sampling sites included all types of functional zones, exhibiting site-specific features of toxicity of LMW PAHs. Except eight sampling sites (Y8, Y10, Y11, E4, E5, S1, S3, and S4), 6-ring PAHs accounts for over 50\% of toxicity of HMW PAHs with maximal contribution proportion of $99.50 \%$ (Figure 3c). For sampling sites including Y10, Y11, E4, E5, S1, S3, and S4, 5-ring PAHs were dominant toxicity contributor of HMW PAHs, while 4-ring PAHs accounted for $73.09 \%$ of toxicity of HMW PAHs at Y8. These eight sampling sites included all types of functional zones, also exhibiting site-specific features of toxicity of HMW PAHs.

Owing to TEF values of 1 , InP and DbA served as the main toxicity contributors for total PAHs. Moreover, BbF was also an important toxicity contributor due to its relatively high detection frequency, concentrations, and TEF value. Interestingly, $\mathrm{BaP}$ that is one of the most common PAHs was not detected in this study. Since $\mathrm{BaP}$ is one of the most toxic compounds among PAHs, it is safe to argue that the toxicity of PAHs in the coastal waters along the coastline of China should increase further when BaP existed with relatively high concentrations.

\section{Potential health risks of PAHs in coastal waters along Chinese coastline}

Potential health risks of PAHs in coastal waters of the study area for both children and adults were express as cancer risks and hazard quotients (Figures 4, S4, and S5). Cancer risks of total PAHs in coastal waters for adults and children were in the ranges of $8.24 \times 10^{-5}-6.34 \times 10^{-4}$ and $2.93 \times 10^{-4}-2.25 \times 10^{-3}$ with the average values of $2.65 \times 10^{-4}$ and $9.40 \times 10^{-4}$, respectively (Figure $4 \mathrm{a}$ ). Based on ranking criterion (Ge et al. 2013), cancer risks of PAHs in coastal waters at $93.75 \%$ and $6.25 \%$ of sampling sites for adults were classified into moderate and low levels, respectively. In contrast, 


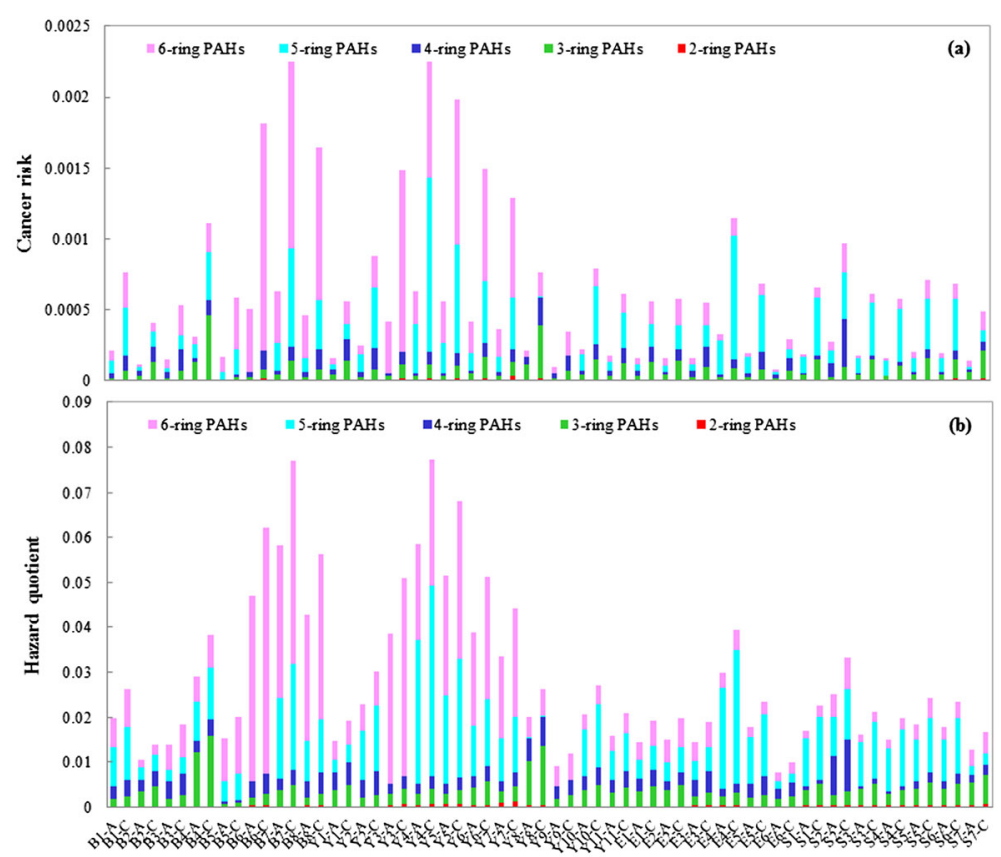

Figure 4. Potential cancer risks (a) and hazard quotients (b) of PAHs in coastal waters. A and C refer to adults and children, respectively.

cancer risks of PAHs in coastal waters at $68.75 \%$ and $31.25 \%$ of sampling sites for children were classified into moderate and high levels, respectively. Moreover, cancer risks of PAHs for children were nearly 3.6 times those for adults, illustrating that children will be more susceptible to potential harm posed by PAHs. Except BaP that was not detected, cancer risks posed by individual PAH congeners for adults/children ranged from negligible/negligible to $2.45 \times 10^{-4} / 8.71 \times 10^{-4}(\mathrm{BbF})$ with average values of $\left(2.38 \times 10^{-6}-6.88 \times 10^{-5}\right) /\left(8.45 \times 10^{-6}-2.44 \times 10^{-4}\right)$, respectively (Figures S4, S5). Except Y8, HMW PAHs served as the dominant health risk contributor in the remaining sites, accounting for $57.36 \%-95.62 \%$ of total cancer risks. Cancer risks posed by 3-ring PAHs accounted for $74.30 \%-99.87 \%$ of those posed by LMW PAHs at all sampling sties while cancer risks of 5-ring and 6-ring PAHs contributed to 59.94\%-97.05\% of cancer risks posed by HMW PAHs at sites except Y8. Cancer risks of PAHs exhibited the site-specific and compound-specific distribution features so that the risk control measures should be unique for different sites.

Hazard quotients of total PAHs in coastal waters for adults and children ranged from $7.59 \times 10^{-3}$ to $5.85 \times 10^{-2}$ and from $1.00 \times 10^{-2}$ to $7.72 \times 10^{-2}$ with the average values of $2.44 \times 10^{-2}$ and $3.22 \times 10^{-2}$, respectively (Figure $4 \mathrm{~b}$ ), all lower than risk safe threshold value of 1.0. Moreover, hazard quotients of PAHs for children were about 1.3 times those for adults, illustrating cancer risks of PAHs were more serious than non-cancer risks for children who are still more susceptible to non-cancer harm of PAHs than adults. Except $\mathrm{BaP}$ that was not detected, hazard quotients of individual $\mathrm{PAH}$ congeners ranged from negligible to $2.26 \times 10^{-2}$ and from negligible to $2.98 \times 10^{-2}$ with the average values of $2.19 \times 10^{-4}-6.34 \times 10^{-3}$ and 

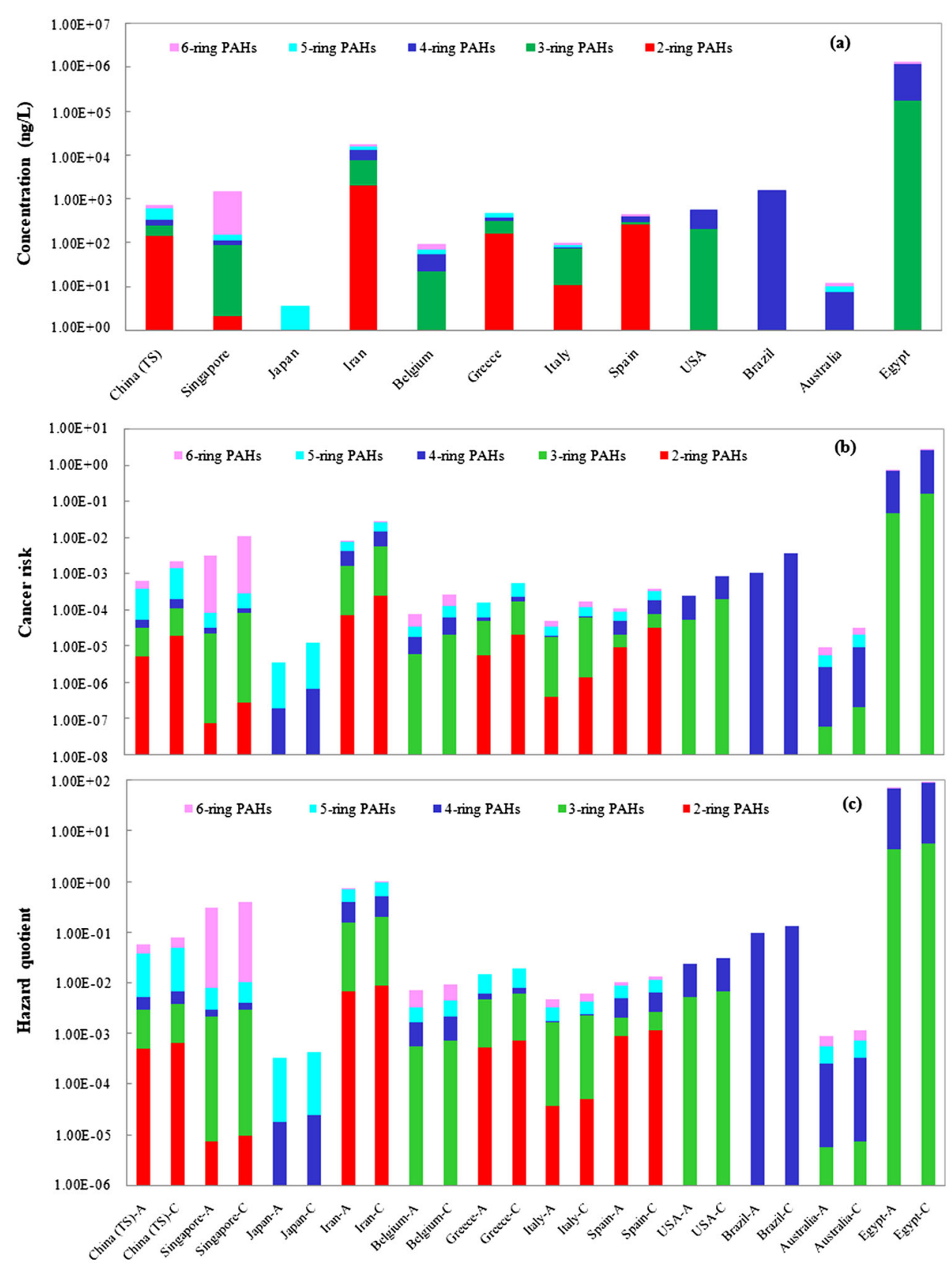

Figure 5. Concentrations (a), potential cancer risk (b), and hazard quotient (c) of PAHs in coastal waters in the world. A and C refer to adults and children, respectively. TS means this study.

$2.89 \times 10^{-4}-8.37 \times 10^{-3}$ for adults and children, respectively (Figures S4, S5). Similar to distribution feature of cancer risks, HMW PAHs mainly contributed to hazard quotients, while 3-ring PAHs served as the dominant contributor for non-cancer risks posed by LMW PAHs and 5-ring and 6-ring PAHs accounted for over 59\% of non-cancer risks posed by HMW PAHs. 


\section{Comparison on potential health risks of PAHs in coastal waters at a global scale}

Concentrations, potential cancer risks, and hazard quotients of PAHs in coastal waters around the world are illustrated in Figure 5. Concentrations of PAHs in coastal waters around the world ranged from $3.56 \mathrm{ng} / \mathrm{L}$ (Japan) to $1.25 \mathrm{mg} / \mathrm{L}$ (Egypt), showing drastic fluctuation. Accordingly, health risks posed by PAHs in coastal waters around the world also exhibited significant variation. Cancer risks of PAHs ranged from $3.57 \times 10^{-6}$ (Japan) to $7.93 \times 10^{-1}$ (Egypt) for adults and from $1.27 \times 10^{-5}$ (Japan) to 2.82 (Egypt) for children. Hazard quotients of PAHs ranged from $3.30 \times 10^{-4}$ (Japan) to 73.15 (Egypt) for adults and from $4.35 \times 10^{-4}$ (Japan) to 96.56 (Egypt) for children, respectively. PAHs in coastal waters of Egypt posed very high cancer risks and unacceptable non-cancer risks for both adults and children. PAHs in coastal waters of Iran, Singapore, and Brazil posed high cancer risks for adults, while those from Iran, Singapore, Brazil, and China exerted high cancer risks for children. PAHs in coastal waters of Japan, Belgium, Italy, and Australia posed low cancer risks for adults, while those from China, Greece, Spain, and USA exerted moderate cancer risks for adults. PAHs in coastal waters of Japan and Australia posed low cancer risks for children, while those from Belgium, Greece, Italy, Spain, and USA exerted moderate cancer risks for children. Except Egypt, non-cancer risks posed by PAHs in coastal waters from other countries were at acceptable levels. Health risks posed by PAHs in this study were higher than those from Japan, Belgium, Greece, Italy, Spain, USA, and Australia but much lower than those from Singapore, Iran, Brazil, and Egypt.

\section{Conclusions}

Concentrations of PAHs in coastal waters along Chinese coastline were in the range of 141.99-717.72 ng/L, exhibiting that moderate and light $\mathrm{PAH}$ pollution occurred at $84.38 \%$ and $15.62 \%$ of sampling sites, respectively. PAHs in most of coastal water samples collected from Haihe Estuary and Shandong Peninsula showed relatively high concentrations. Naph, Phe, BghiP, InP, and DbA were the most frequently detected PAH congeners in coastal waters along the coastline. PAHs in coastal waters at most of sampling sites mainly originated from combustion based on characteristic-ratio source apportionment. PAHs exerted high ecological risks to $59.38 \%$ of sampling sites and moderate risks to $40.63 \%$ of sampling sites based on risk quotients. Toxic equivalent quotient of PAHs ranged from 2.86 to $126.52 \mathrm{ng} / \mathrm{L} \mathrm{BaP}$ with $\mathrm{InP}$ and $\mathrm{DbA}$ serving as main toxicity contributors for total PAHs. Cancer risks of total PAHs in coastal waters for adults and children were in the ranges of $8.24 \times 10^{-5}-6.34 \times 10^{-4}$ and $2.93 \times 10^{-4}-2.25 \times 10^{-3}$. Cancer risks of PAHs in coastal waters at $93.75 \%$ of sampling sites for adults were classified into moderate level, while those at $31.25 \%$ of sampling sites for children were classified into high level. Hazard quotients for adults and children ranged from $7.59 \times 10^{-3}$ to $5.85 \times 10^{-2}$ and from $1.00 \times 10^{-2}$ to $7.72 \times 10^{-2}$ to exert acceptable non-cancer risks. Potential health risks of PAHs in coastal waters along coastline of China were higher than those of Japan, Belgium, Greece, Italy, Spain, USA, and Australia, but much lower than those of Singapore, Iran, Brazil, and Egypt. These findings indicate that PAH pollution has become a crucial stress affecting the 
sustainable development of the coastal regions. It is urgent to take effective and efficient measures to control PAH pollution in the coastal regions.

\section{Acknowledgements}

The authors would like to thank the reviewers for their valuable suggestions and comments on the manuscript.

\section{Funding}

This work was supported by National Natural Science Foundation of China (Nos. 41671319 and 41877131), One Hundred Talents Program of Chinese Academy of Sciences (Nos. Y629041021 and Y610061033), Taishan Scholar Program of Shandong Province, Key Research Program of Frontier Sciences of CAS (No. QYZDJ-SSW-DQC015), Two-Hundred Talents Plan of Yantai (Y739011021), and Research Program of CAS Key Laboratory of Coastal Environmental Processes and Ecological Remediation (No. 1189010002).

\section{References}

Agah H, Mehdinia A, Bastami KD, et al. 2017. Polycyclic aromatic hydrocarbon pollution in the surface water and sediments of Chabahar Bay, Oman Sea. Mar Pollut Bull 115:515-524. doi: 10.1016/j.marpolbul.2016.12.032

Ahmed OE, Mahmoud SA, and El Nady MM. 2017. Organic sources in the Egyptian seawater around Alexandria coastal area as integrated from polycyclic aromatic hydrocarbons (PAHs). Egypt J Petrol 26:819-826. doi:10.1016/j.ejpe.2016.10.016

Akhbarizadeh R, Moore F, Keshavarzi B, et al. 2016. Aliphatic and polycyclic aromatic hydrocarbons risk assessment in coastal water and sediments of Khark Island, SW Iran. Mar Pollut Bull 108:33-45. doi:10.1016/j.marpolbul.2016.05.004

Barro R, Regueiro J, Llompart M, et al. 2009. Analysis of industrial contaminants in indoor air: Part 1. Volatile organic compounds, carbonyl compounds, polycyclic aromatic hydrocarbons and polychlorinated biphenyls. J Chromatogr A 1216(3):540-566. doi:10.1016/ j.chroma.2008.10.117

Birks SJ, Cho S, Taylor E, et al. 2017. Characterizing the PAHs in surface waters and snow in the Athabasca region: Implications for identifying hydrological pathways of atmospheric deposition. Sci Total Environ 603-604:570-583. doi:10.1016/j.scitotenv.2017.06.051

Budzinski H, Jones I, Bellocq J, et al. 1997. Evaluation of sediment contamination by polycyclic aromatic hydrocarbons in the Gironde estuary. Mar Chem 58:85-97. doi:10.1016/S03044203(97)00028-5

Cai M, Lin Y, Chen M, et al. 2017. Improved source apportionment of PAHs and Pb by integrating $\mathrm{Pb}$ stable isotopes and positive matrix factorization application (PAHs): A historical record case study from the northern South China Sea. Sci Total Environ 609:577-586. doi:10.1016/ j.scitotenv.2017.07.190

Cao Z, Liu J, Luan Y, et al. 2010. Distribution and ecosystem risk assessment of polycyclic aromatic hydrocarbons in the Luan River, China. Ecotoxicology 19(5):827-837. doi:10.1007/ s10646-010-0464-5

Capone DG, and Bauer JE. 1992. Environmental Microbiology. Clarendon Press, Oxford

Cocci P, Capriotti M, Mosconi G, et al. 2017. Alterations of gene expression indicating effects on estrogen signaling and lipid homeostasis in seabream hepatocytes exposed to extracts of seawater sampled from a coastal area of the central Adriatic Sea (Italy). Mar Environ Res 123: 25-37. doi:10.1016/j.marenvres.2016.11.001

Dennison WC. 2008. Environmental problem solving in coastal ecosystems: A paradigm shift to sustainability. Estuar Coast Shelf S 77:185-196. doi:10.1016/j.ecss.2007.09.031 
Gao P, Mao D, Luo Y, et al. 2012. Occurrence of sulfonamide and tetracycline-resistant bacteria and resistance genes in aquaculture environment. Water Res 46:2355-2364. doi:10.1016/ j.watres.2012.02.004

Ge J, Woodward LA, Li QX, et al. 2013. Composition, distribution and risk assessment of organochlorine pesticides in soils from the Midway Atoll, North Pacific Ocean. Sci Total Environ 452-453:421-426. doi:10.1016/j.scitotenv.2013.03.015

Li J, Dong H, Xu X, et al. 2016. Prediction of the bioaccumulation of PAHs in surface sediments of Bohai Sea, China and quantitative assessment of the related toxicity and health risk to humans. Mar Pollut Bull 104:92-100. doi:10.1016/j.marpolbul.2016.02.005

Li J, Li F, and Liu Q. 2017. PAHs behavior in surface water and groundwater of the Yellow River estuary: Evidence from isotopes and hydrochemistry. Chemosphere 178:143-153. doi:10.1016/ j.chemosphere.2017.03.052

Li P, Cao J, Diao X, et al. 2015. Spatial distribution, sources and ecological risk assessment of polycyclic aromatic hydrocarbons in surface seawater from Yangpu Bay, China. Mar Pollut Bull 93:53-60. doi:10.1016/j.marpolbul.2015.02.015

Liu S, Liu X, Liu M, et al. 2016. Levels, sources and risk assessment of PAHs in multi-phases from urbanized river network system in Shanghai. Environ Pollut 219:555-567. doi:10.1016/ j.envpol.2016.06.010

Man YB, Kang Y, Wang HS, et al. 2013. Cancer risk assessments of Hong Kong soils contaminated by polycyclic aromatic hydrocarbons. J Hazard Mater 261:770-776. doi:10.1016/ j.jhazmat.2012.11.067

Marini M, and Frapiccini E. 2013. Persistence of polycyclic aromatic hydrocarbons in sediments in the deeper area of the Northern Adriatic Sea (Mediterranean Sea). Chemosphere 90: 1839-1846. doi:10.1016/j.chemosphere.2012.09.080

McGrath JA, and Di Toro DM. 2009. Validation of the target lipid model for toxicity assessment of residual petroleum constituents: monocyclic and polycyclic aromatic hydrocarbons. Environ Toxicol Chem 28(6):1130-1148. doi:10.1897/08-271.1

Meng W, Hu B, He M, et al. 2017. Temporal-spatial variations and driving factors analysis of coastal reclamation in China. Estuar Coast Shelf Sci 191:39-49. doi:10.1016/j.ecss.2017.04.008

Monteyne E, Roose P, and Janssen CR. 2013. Application of a silicone rubber passive sampling technique for monitoring PAHs and PCBs at three Belgian coastal harbours. Chemosphere 91: 390-398. doi:10.1016/j.chemosphere.2012.11.074

Mostafa AR, Wade TL, Sweet ST, et al. 2009. Distribution and characteristics of polycyclic aromatic hydrocarbons (PAHs) in sediments of Hadhramout coastal area, Gulf of Aden, Yemen. J Mar Syst 78(1):1-8. doi:10.1016/j.jmarsys.2009.02.002

Obbard JP, Wurl O, and Bayen S. 2007. Persistent Organic Pollutants in Singapore's Marine Environment. Dev Environ Sci 7:657-720. doi:10.1016/S1474-8177(07)07015-5

Pandey SK, Kim K-H, and Brown RJC. 2011. A review of techniques for the determination of polycyclic aromatic hydrocarbons in air. TrAC-Trend Anal Chem 30(11):1716-1739. doi: 10.1016/j.trac.2011.06.017

Purcaro G, Moret S, and Conte LS, 2013. Overview on polycyclic aromatic hydrocarbons: Occurrence, legislation and innovative determination in foods. Talanta 105:292-305. doi: 10.1016/j.talanta.2012.10.041

Qamar Z, Khan S, Khan A, et al. 2017. Appraisement, source apportionment and health risk of polycyclic aromatic hydrocarbons (PAHs) in vehicle-wash wastewater, Pakistan. Sci Total Environ 605-606:106-113. doi:10.1016/j.scitotenv.2017.06.152

Qin N, He W, Kong X-Z, et al. 2013. Ecological risk assessment of polycyclic aromatic hydrocarbons (PAHs) in the water from a large Chinese lake based on multiple indicators. Ecol Indic 24:599-608. doi:10.1016/j.ecolind.2012.08.019

Rajasekhar B, Nambi IM, and Govindarajan SK. 2018. Human health risk assessment of ground water contaminated with petroleum PAHs using Monte Carlo simulations: A case study of an Indian metropolitan city. J Environ Manage 205:183-191. doi:10.1016/j.jenvman.2017.09.078

Ranjbar Jafarabadi A, Riyahi Bakhtiari A, and Shadmehri Toosi A. 2017. Comprehensive and comparative ecotoxicological and human risk assessment of polycyclic aromatic hydrocarbons 
(PAHs) in reef surface sediments and coastal seawaters of Iranian Coral Islands, Persian Gulf. Ecotoxicol Environ Saf 145:640-652. doi:10.1016/j.ecoenv.2017.08.016

Sánchez-Avila J, Quintana J, Ventura F, et al. 2010. Stir bar sorptive extraction-thermal desorption-gas chromatography-mass spectrometry: An effective tool for determining persistent organic pollutants and nonylphenol in coastal waters in compliance with existing Directives. Mar Pollut Bull 60:103-112. doi:10.1016/j.marpolbul.2009.08.028

Sankoda K, Toda I, Sekiguchi K, et al. 2017. Aqueous secondary formation of brominated, chlorinated, and mixed halogenated pyrene in presence of halide ions. Chemosphere 171:399-404. doi:10.1016/j.chemosphere.2016.12.044

Sarria-Villa R, Ocampo-Duque W, Páez M, et al. 2016. Presence of PAHs in water and sediments of the Colombian Cauca River during heavy rain episodes, and implications for risk assessment. Sci Total Environ 540:455-465. doi:10.1016/j.scitotenv.2015.07.020

Shaw M, Tibbetts IR, and Müller JF. 2004. Monitoring PAHs in the Brisbane River and Moreton Bay, Australia, using semipermeable membrane devices and EROD activity in yellowfin bream, Acanthopagrus australis. Chemosphere 56:237-246. doi:10.1016/j.chemosphere.2004.03.003

Silva TF, Azevedo DA, and Aquino Neto FR. 2007. Distribution of polycyclic aromatic hydrocarbons in surface sediments and waters from Guanabara Bay, Rio de Janeiro, Brazil. J Braz Chem Soc 18:628-637. doi:10.1590/S0103-50532007000300021

Sun J-H, Wang G-L, Chai Y, et al. 2009. Distribution of polycyclic aromatic hydrocarbons (PAHs) in Henan Reach of the Yellow River, Middle China. Ecotoxicol Environ Saf 72: 1614-1624. doi:10.1016/j.ecoenv.2008.05.010

USEPA (U.S. Environmental Protection Agency). 2004. Risk Assessment Guidance for Superfund Volume I: Human Health Evaluation Manual (Part E, Supplemental Guidance for Dermal Risk Assessment). Office of Superfund Remediation and Technology Innovation, Washington, DC

USEPA (U.S. Environmental Protection Agency). 2014. Priority Pollutant List. Available on https://www.epa.gov/sites/production/files/2015-09/documents/priority-pollutant-list-epa.pdf

USEPA (U.S. Environmental Protection Agency). 2016. Regional Screening Levels (RSLs) - User's Guide. Available on https://www.epa.gov/risk/regional-screening-levels-rsls-users-guide-may-2016

Valavanidis A, Vlachogianni Th, Triantafillaki S, et al. 2008. Polycyclic aromatic hydrocarbons in surface seawater and in indigenous mussels (Mytilus galloprovincialis) from coastal areas of the Saronikos Gulf (Greece). Estuar Coast Shelf S 79:733-739. doi:10.1016/j.ecss.2008.06.018

Wang J, Lu J, Zhang Y, et al. 2018. Metagenomic analysis of antibiotic resistance in coastal industrial mariculture systems. Bioresource Technol 253:235-243. doi:10.1016/j.biortech.2018.01.035

Wen X, Feng Q, Lu J, et al. 2018. Risk assessment and source identification of coastal groundwater nitrate in northern China using dual nitrate isotopes combined with Bayesian mixing model. Hum Ecol Risk Assess 24:1043-1057. doi:10.1080/10807039.2017.1405722

Williams AK, Bacosa HP, and Quigg A. 2017. The impact of dissolved inorganic nitrogen and phosphorous on responses of microbial plankton to the Texas City "Y" oil spill in Galveston Bay, Texas (USA). Mar Pollut Bull 121:32-44. doi:10.1016/j.marpolbul.2017.05.033

Wu J, Lu J, Li L, et al. 2018. Pollution, ecological-health risks, and sources of heavy metals in soil of the northeastern Qinghai-Tibet Plateau. Chemosphere 201:234-242. doi:10.1016/ j.chemosphere.2018.02.122.

$\mathrm{Wu} J$, Lu J, Luo Y, et al. 2016. An overview on the organic pollution around the Qinghai-Tibet Plateau: the thought-provoking situation. Environ Int 97:264-272. doi:10.1016/j.envint.2016.09.019

Yuan X, Yang X, Zhang A, et al. 2017. Distribution, potential sources and ecological risks of two persistent organic pollutants in the intertidal sediment at the Shuangtaizi Estuary, Bohai Sea of China. Mar Pollut Bull 114: 419-427. doi:10.1016/j.marpolbul.2016.09.058

Yunker MB, Macdonald RW, Vingarzan R, et al. 2002. PAHs in the Fraser River basin: A critical appraisal of PAH ratios as indicators of PAH source and composition. Org Geochem 33: 489-515. doi:10.1016/S0146-6380(02)00002-5

Zhang A, Zhao S, Wang L, et al. 2016. Polycyclic aromatic hydrocarbons (PAHs) in seawater and sediments from the northern Liaodong Bay, China. Mar Pollut Bull 113:592-599. doi:10.1016/ j.marpolbul.2016.09.005 
Zheng B, Wang L, Lei K, et al. 2016. Distribution and ecological risk assessment of polycyclic aromatic hydrocarbons in water, suspended particulate matter and sediment from Daliao River estuary and the adjacent area, China. Chemosphere 149:91-100. doi:10.1016/j.chemosphere.2016.01.039

Zheng Y, Lin Z, Li H, et al. 2014. Assessing the polycyclic aromatic hydrocarbon (PAH) pollution of urban stormwater runoff: A dynamic modeling approach. Sci Total Environ 481:554-563. doi:10.1016/j.scitotenv.2014.02.097

Zhu Y-G, Zhao Y, Li B, et al. 2017. Continental-scale pollution of estuaries with antibiotic resistance genes. Nat Microbiol 2: 16270. doi:10.1038/nmicrobiol.2016.270 